\title{
Identification of biomarkers in ductal carcinoma in situ of the breast with microinvasion
}

\author{
Yasuhiro Okumura ${ }^{1}$, Yutaka Yamamoto1, Zhenhuan Zhang1, \\ Tatsuya Toyama ${ }^{2}$, Teru Kawasoe ${ }^{1}$, Mutsuko Ibusuki ${ }^{1}$, Yumi Honda ${ }^{3}$, Ken- \\ ichi Iyama ${ }^{3}$, Hiroko Yamashita ${ }^{2}$ and Hirotaka Iwase*1
}

\begin{abstract}
Address: ${ }^{1}$ Department of Breast and Endocrine Surgery, Graduate School of Medical and Pharmaceutical Sciences, Kumamoto University, Honjo 1-1-1, Kumamoto 860-8556, Japan, 2Department of Oncology and Immunology, Graduate School of Medical Sciences, Nagoya City University, Kawasumi 1, Mizuho-ku, Nagoya 467-8601, Japan and ${ }^{3}$ Department of Pathology, Kumamoto University Hospital, Honjo 1-1-1, Kumamoto 8608556, Japan

Email: Yasuhiro Okumura - sigeoku@yahoo.co.jp; Yutaka Yamamoto - ys-yama@triton.ocn.ne.jp; Zhenhuan Zhang - zhangzhen@mail.nih.gov; Tatsuya Toyama - t.toyama@med.nagoya-cu.ac.jp; Teru Kawasoe - tkawasoe@kumamoto-u.ac.jp;

Mutsuko Ibusuki - pellegrino2002jp@yahoo.co.jp; Yumi Honda - yumih@kumamoto-u.ac.jp; Ken-ichi Iyama - iyama@kumamoto-u.ac.jp;

Hiroko Yamashita - hirokoy@med.nagoya-cu.ac.jp; Hirotaka Iwase* - hiwase@kumamoto-u.ac.jp

* Corresponding author
\end{abstract}

Published: 6 October 2008

BMC Cancer 2008, 8:287 doi:10.1186/147I-2407-8-287

This article is available from: http://www.biomedcentral.com/I47I-2407/8/287

(c) 2008 Okumura et al; licensee BioMed Central Ltd.

This is an Open Access article distributed under the terms of the Creative Commons Attribution License (http://creativecommons.org/licenses/by/2.0), which permits unrestricted use, distribution, and reproduction in any medium, provided the original work is properly cited.
Received: 17 January 2008

Accepted: 6 October 2008

\begin{abstract}
Background: Widespread use of mammography in breast cancer screening has led to the identification of increasing numbers of patients with ductal carcinoma in situ (DCIS). DCIS of the breast with an area of focal invasion I mm or less in diameter is defined as DCIS with microinvasion, DCIS-Mi. Identification of biological differences between DCIS and DCIS-Mi may aid in understanding of the nature and causes of the progression of DCIS to invasiveness.
\end{abstract}

Methods: In this study, using resected breast cancer tissues, we compared pure DCIS (52 cases) and DCIS-Mi (28 cases) with regard to pathological findings of intraductal lesions, biological factors, apoptosis-related protein expression, and proliferative capacity through the use of immunohistochemistry and the TdT-mediated dUTP-biotin nick end labeling (TUNEL) method.

Results: There were no differences in biological factors between DCIS and DCIS-Mi, with respect to levels of estrogen receptor, progesterone receptor, and human epidermal growth factor receptor type 2. The frequency of necrosis and positive expression ratio of survivin and Bax were significantly higher in DCIS-Mi than in DCIS. In addition, apoptotic index, $\mathrm{Ki}-67$ index, and positive $\mathrm{BCl}-2$ immunolabeling tended to be higher in DCIS-Mi than in DCIS. Multivariate analysis revealed that the presence of necrosis and positive survivin expression were independent factors associated with invasion.

Conclusion: Compared with DCIS, DCIS-Mi is characterized by a slightly elevated cell proliferation capacity and enhanced apoptosis within the intraductal lesion, both of which are thought to promote the formation of cell necrotic foci. Furthermore, the differential expression of survivin may serve in deciding the response to therapy and may have some prognostic significance. 


\section{Background}

Ductal carcinoma in situ (DCIS) is thought to be a precursor of invasive ductal carcinoma (IDC) and is defined as a lesion in which cancer cells do not grow beyond the basal membrane of the mammary duct [1]. Since the introduction of mammography in breast cancer screening, increasing numbers of DCIS are now being identified [2]. About 10 years ago, DCIS accounted for only $1-5 \%$ of all newly diagnosed cases of breast cancer, whereas the frequency has increased recently to $15-20 \%[3,4]$. According to the criteria of the American Joint Committee on Cancer (AJCC), IDC with a microscopic focus of invasion less than or equal to $0.1 \mathrm{~cm}$ in the longest dimension, is defined as T1mic [5]. In situations where there are multiple foci of microinvasion, the classification is based on the largest focus, rather than the sum of all the individual foci and therefore, if the size of the largest focus is less than 0.1 $\mathrm{cm}$, the lesion will still be defined as T1mic [5]. This ductal carcinoma in situ with microinvasion, known as DCIS$\mathrm{Mi}$, is identified in $10-20 \%$ of cases thought to be DCIS, through the use of preoperative diagnostic imaging and cytology; it is considered to represent the interim stage in the progression from DCIS to IDC [6-8]. Histopathological factors including architectural subtypes, nuclear grade, the presence of necrosis, tumor size, and the distance to the surgical stump have already been reported as predictors of the risk of local recurrence in DCIS [9-11]. Further analyses of the biological parameters will make the prediction of local recurrence in DCIS more accurate. At present, various biological parameters have been reported as prognostic factors for DCIS. Overexpression of human epidermal growth factor receptor 2 (HER2), decreased expression of estrogen receptor (ER), overexpression of p53, and positive Ki-67 staining, have all been shown to correlate with nuclear grade in both DCIS and IDC $[8,12-$ $16]$. It has also been reported that endometase/matrilysin2 and tissue inhibitors of metalloproteinase- 2 and -4 are overexpressed in the invasive component of DCIS [17]. However, there have been few reports investigating the status of apoptosis and apoptosis-related factors in DCIS. In particular, the survivin gene, shown to be expressed in proliferating cells such as fetal and various cancer cells, is known to be a member of the inhibitor of apoptosis protein (IAP) family, which promotes cell proliferation and inhibits apoptosis [18-21].

Tumor progression may be induced or associated by alterations in the proliferative capacity and the apoptosis potential, and the findings may find some basic and applied interpretations especially useful for confirming a diagnosis, and in building up prognostic criteria. Therefore, apoptosis-related factors (apoptotic index, survivin, Bcl-2, Bax), cell proliferation/cycle-related factors (Ki-67, p53, p21, cyclinD1, Rb), and other factors are analyzed in DCIS and DCIS-Mi in this investigation.

\section{Methods \\ Patients}

The study population consisted of 52 patients with DCIS and 28 with DCIS-Mi, diagnosed by postoperative histopathological examinations after undergoing surgery for the diagnosis of non-invasive or invasive ductal carcinoma of the breast at the Kumamoto University Hospital or the Nagoya City University Hospital from 1990 to 2005. The median age was 56 years old (range, 36-86) in patients with DCIS and 50 (range, 32-71) in patients with DCIS-Mi. The median follow-up period was 62 months (range, 13-140) in DCIS and 54 (range, 14-182) in DCIS-Mi (Table 1). To date, of the DCIS-Mi patients, one has had a recurrence in the contralateral breast and another has developed bone metastasis. There have been no deaths. The information was obtained from the patient records. The ethics committee of Kumamoto University and Nagoya City University approved the study protocol and confirmed that it was conducted in accordance with the guidelines of the 1975 Declaration of Helsinki. Informed consent was obtained from all patients before or after surgery. Histological diagnosis was made by 2 specialized pathologists. The histological subtypes were determined on the predominant area occupying most of the lesion, although in some cases multiple histological subtypes were mixed. When there were multiple foci of microinvasion, if the size of the largest focus was less than $0.1 \mathrm{~cm}$, the lesion was regarded as DCIS-Mi.

Histological variables, including classification of histological subtypes, grade of nuclear atypia, and the presence of necrotic foci, were evaluated on slides stained with hematoxylin-eosin (HE). According to the Van Nuys classification [22], cases were classified into three groups: highnuclear grade (Grade 3); non-high nuclear grade with necrosis (Grade 2); and non-high nuclear grade without necrosis (Grade 1). In some cases, microinvasion was confirmed by staining the basal membrane with type IV collagenase [23].

\section{Immunohistochemistry}

Resected specimens were fixed in 10\% buffered-formalin and embedded in paraffin within $24-48$ hours. Four- $\mu \mathrm{m}$ sections were cut from this paraffin block and mounted on adhesive-coated slides (Aminosilane-coated slides; MATSUNAMI GLASS Co. Ltd., Japan) for immunohistochemistry [15]. The sections were deparaffinized in xylene $(5 \times 5$ minutes $)$ and ethanol $(2 \times 100 \%, 1 \times 90 \%, 1 \times$ $80 \%, 1 \times 70 \%)$. Subsequently, antigen retrieval was performed in citrate buffer at $\mathrm{pH} 9$ for survivin as previously described [24], using a microwave oven (after boiling, $3 \times$ 10 minutes at $750 \mathrm{~W}$ or $4 \times 15$ minutes at $170 \mathrm{~W})$. After leaving at room temperature for 20 minutes, sections were immersed in phosphate-buffered saline (PBS). Endogenous peroxidase was blocked by incubation with $3 \%$ 
Table I: Histological characteristics of intraductal component in ductal carcinoma in situ (DCIS) and in ductal carcinoma in situ with microinvasion (DCIS-Mi)

\begin{tabular}{|c|c|c|c|}
\hline & DCIS & DCIS-Mi & \\
\hline Number of patients & 52 & 28 & \\
\hline Median follow-up period, months (range) & $62(3-140)$ & $54(14-182)$ & \\
\hline Median age, years (range) & $56(36-86)$ & $50(32-7 I)$ & \\
\hline \multicolumn{4}{|l|}{ Architectural classification } \\
\hline comedo & $8(15.4 \%)$ & $10(35.7 \%)$ & $P=0.073$ \\
\hline Papillary & $21(40.4 \%)$ & $10(35.7 \%)$ & (comedo vs others) \\
\hline cribriform & $15(28.8 \%)$ & $4(14.3 \%)$ & \\
\hline solid & $4(7.7 \%)$ & $4(14.3 \%)$ & \\
\hline low papillary & $4(7.7 \%)$ & $0(0)$ & \\
\hline \multicolumn{4}{|l|}{ Nuclear Grade } \\
\hline Grade I & 21 (40.4\%) & $7(25)$ & $P=0.16$ \\
\hline Grade 2 & $29(55.8 \%)$ & $18(64.3)$ & (I vs. 2,3$)$ \\
\hline Grade 3 & $2(3.9 \%)$ & $3(10.7)$ & \\
\hline \multicolumn{4}{|l|}{ Necrosis } \\
\hline absent & $25(48.1 \%)$ & $4(14.3 \%)$ & $P=0.0017$ \\
\hline Present & 27 (51.9\%) & $24(85.7 \%)$ & \\
\hline \multicolumn{4}{|l|}{ Van Nuys Classification* } \\
\hline Grade I & $25(48.1 \%)$ & $4(14.3 \%)$ & $P=0.0017$ \\
\hline Grade 2 & $25(48.1 \%)$ & $21(75 \%)$ & (I vs. 2,3 ) \\
\hline Grade 3 & $2(3.9 \%)$ & $3(10.7 \%)$ & \\
\hline
\end{tabular}

* Van Nuys Classification: Grade I = non-high nuclear grade without necrosis; Grade 2 = non-high nuclear grade with necrosis; Grade 3 = highnuclear grade.

$\mathrm{H}_{2} \mathrm{O}_{2}$ in methanol for 10 minutes. Sections were washed with PBS ( $3 \times 5$ minutes) followed by blocking with $5 \%$ skimmed milk for 20 minutes [25].

Immunohistochemical staining was performed by the avidin-biotin complex (ABC) method using the Vectastain ABC kit for ER, progesterone receptor (PgR), HER2, Ki-67, survivin, p53, p21, cyclin D1, and Rb, (monoclonal antibodies, DAKO, Netherlands) and by the immuno-enzyme polymer method (indirect method, EnVision system, DAKO, Netherlands) using Histofine Simple Stain MAX PO (Nichirei Bioscience, Tokyo Japan) for Bcl-2 and Bax [26]. Sections were incubated with dilutions of primary antibodies for 60 minutes at room temperature. After washing with PBS $(3 \times 5$ minutes $)$, sections were incubated with biotinylated secondary antibodies for $30 \mathrm{~min}$ utes. Following this, the sections were washed again with PBS ( $3 \times 5$ minutes) and then reacted with an ABC solution for 30 minutes at room temperature. After a further washing with PBS $(3 \times 5$ minutes $)$, the sections were stained with 3, 3'-diaminobenzidine (DAB) substrate solution.

In the immuno-enzyme polymer (indirect) method, sections were incubated with dilutions of primary antibodies at $4{ }^{\circ} \mathrm{C}$ overnight. After washing with PBS ( $3 \times 5$ minutes $)$, sections were reacted with the Histofine Simple Stain MAX PO (mouse or rabbit), washed again with PBS $(3 \times 5$ minutes), and then stained with DAB solution [25]. Nuclear staining of all sections was done with hematoxy- lin. The sections were mounted after dehydration $(1 \times$ $70 \%, 1 \times 80 \%, 1 \times 90 \%, 2 \times 100 \%$ ethanol) and penetration ( $3 \times$ xylene for 3 minutes). Details of the primary antibodies used in this study are shown in Table 2.

\section{Evaluation of immunohistochemistry}

For Ki-67 expression, the percentage of cancer cells with positively-stained nuclei was determined. Nuclear labeling of more than $10 \%$ of all observed cancer cells was regarded as positive for ER, PgR, p53, p21, cyclin D1, and $\mathrm{Rb}$ [25]. HER2 expression was categorized into no staining $(0)$, weak staining $(+1)$, moderate staining $(+2)$, or strong staining $(+3)$, and was regarded as positive only when cancer cells showed strong staining $(+3)[15]$. Staining of more than $5 \%$ of all observed cancer cells was regarded as positive for survivin, Bcl-2, and Bax [20,27].

\section{Apoptosis}

Apoptosis was detected by the TdT-mediated dUTP-biotin nick end labeling (TUNEL) method using ApopTag Peroxidase In Situ Apoptosis Detection Kit (S7100; Chemicon International, CA, USA) [28]. After deparaffinization, sections were incubated with Proteinase $\mathrm{K}$ for 15 minutes at room temperature and immersed in pure water. After this, the sections were incubated with $3 \% \mathrm{H}_{2} \mathrm{O}_{2}$ for 5 minutes at room temperature followed by washing with PBS $(2 \times$ 5 minutes). Sections were incubated with equilibration buffer for at least 10 minutes at room temperature and then with working strength TdT enzyme at $37^{\circ} \mathrm{C}$ for 60 minutes, at which point the sections were incubated with 
Table 2: Details of immunohistochemistry and the antibodies

\begin{tabular}{|c|c|c|c|c|c|c|c|}
\hline Antibody & Source & Clone & Dilution & Pretreatment & Citrate buffer & Incubation & Detection system \\
\hline ER & DAKO & ID5 & $\mathrm{I} / 50$ & $4 \times 15 \min M W$ & $\mathrm{pH} 6$ & I h RT & $A B C$ \\
\hline $\mathrm{PgR}$ & DAKO & 636 & $1 / 800$ & $4 \times 15 \min M W$ & $\mathrm{pH} 6$ & I h RT & $A B C$ \\
\hline HER2 & DAKO & & $1 / 300$ & $4 \times 15 \min M W$ & $\mathrm{pH} 6$ & I h RT & $A B C$ \\
\hline $\mathrm{Ki}-67$ & DAKO & MIB-I & $1 / 50$ & $3 \times 10 \min M W$ & $\mathrm{pH} 9$ & I h RT & $A B C$ \\
\hline $\mathrm{Bcl}-2$ & DAKO & 124 & $1 / 50$ & $3 \times 10 \min M W$ & $\mathrm{pH} 9$ & $\mathrm{ON} 4^{\circ} \mathrm{C}$ & En-Vision \\
\hline Bax & DAKO & & $1 / 50$ & $3 \times 10 \min \mathrm{MW}$ & $\mathrm{pH} 6$ & $\mathrm{ON} 4^{\circ} \mathrm{C}$ & En-Vision \\
\hline Survivin & SantaC & D-8 & $1 / 50$ & $3 \times 10 \min M W$ & $\mathrm{pH} 9$ & I h RT & $A B C$ \\
\hline p53 & DAKO & DO-7 & $1 / 50$ & $3 \times 10 \min M W$ & $\mathrm{pH} 9$ & I h RT & $A B C$ \\
\hline p21 & DAKO & SXII8 & $1 / 25$ & $3 \times 10 \min M W$ & $\mathrm{pH} 9$ & I h RT & $A B C$ \\
\hline cyclinDI & NovoC & P2DIIFII & $1 / 50$ & $3 \times 10 \min M W$ & $\mathrm{pH} 9$ & I h RT & $A B C$ \\
\hline $\mathrm{Rb}$ & NovoC & $|3 \mathrm{~A}| 0$ & $1 / 100$ & $3 \times 10 \min M W$ & $\mathrm{pH} 6$ & I h RT & $A B C$ \\
\hline
\end{tabular}

$\mathrm{ER}=$ estrogen receptor; $\mathrm{PgR}=$ progesterone receptor; $\mathrm{MW}=$ microwave; $\mathrm{RT}=$ room temperature; $\mathrm{ON}=$ overnight; Santa $\mathrm{C}=$ Santa $\mathrm{Cruz} ;$ NovoC $=$ NovoCastra.

working strength stop/wash buffer for 10 minutes after being agitated for 15 seconds at room temperature, followed by washing with PBS $(2 \times 1$ minute). Sections were then incubated with anti-digoxigenin conjugate for 30 minutes at room temperature followed by washing with PBS ( $4 \times 2$ minutes). Sections were stained with DAB solution, dehydrated, and mounted. To quantitate apoptosis, the mean number of positive nuclei per 1000 counted nuclei/field was determined in three fields within the cancerous areas of the intraductal components. The mean number of positive nuclei was defined as the apoptotic index.

\section{Statistical methods}

The statistical tests were utilized to examine the difference in each factor between DCIS and DCIS-Mi. Quantitative analyses (Ki-67 and apoptotic index) were performed using the Mann-Whitney U test; all other factors were analyzed with the Chi-squared test and Fisher's exact test. For all comparisons, differences were considered significant when the $P$-value was less than 0.05 . Statistical analyses were performed using the statistical software JMP Japanese Version 4.0 (SAS).

\section{Results \\ Histological evaluation}

Results showed that the comedo type tended to be found more frequently in DCIS-Mi (36\%) than in DCIS (18\%), although this difference did not reach statistical significance $(P=0.073)$. There was no difference in nuclear grade between the two groups but a necrotic focus was found at a significantly higher frequency in DCIS-Mi $(85.7 \%)$ than in DCIS $(51.9 \%)(P=0.0017)$. According to the Van Nuys classification, which evaluates both nuclear grade and necrosis, the grade of malignancy was significantly higher in DCIS-Mi (14.3\%, Grade 1) than in DCIS
(48.1\%, Grade 1) $(P=0.0017$, Grade 1 vs. Grade 2 and 3) (Table 2).

Relative expression of hormone receptors, HER2, and Ki67: DCIS vs. DCIS-Mi

There was no significant difference between DCIS and DCIS-Mi in expression levels of universal biological factors such as ER, PgR, and HER2. The Ki-67 index tended to be higher in DCIS-Mi $(22.8 \pm 2.0 \%)$ than in DCIS $(17.9 \pm$ $1.5 \%)$, although the difference was not statistically significant $(P=0.052)$ (Table 3$)$. Representative microscopic views of immunohistochemical detection were shown in Fig. 1.

\section{Relative expression of apoptosis-related markers: DCIS vs. DCIS-Mi}

The relative expressions of the apoptosis-related markers in DCIS and DCIS-Mi are shown in Table 4. Apoptotic index tended to be higher in DCIS-Mi $(0.29 \pm 0.06 \%)$

Table 3: Hormone Receptor status, HER2 status and Ki-67 index in DCIS and DCIS-Mi

\begin{tabular}{lrrl}
\hline & DCIS & DCIS-Mi & P-value \\
\hline $\begin{array}{l}\text { Estrogen Receptor } \\
\text { positive }\end{array}$ & $38(73.1 \%)$ & $19(67.9 \%)$ & 0.62 \\
$\quad$ negative & $14(26.9 \%)$ & $9(32.1 \%)$ & \\
$\begin{array}{l}\text { Progesterone Receptor } \\
\quad \text { positive }\end{array}$ & $37(71.2 \%)$ & $16(57.1 \%)$ & 0.21 \\
$\quad \begin{array}{l}\text { Negative } \\
\text { c-erbB-2 }\end{array}$ & $15(28.9 \%)$ & $12(42.9 \%)$ & \\
$\quad \begin{array}{l}\text { (1+,2+ } \\
3+\end{array}$ & $43(82.7 \%)$ & $22(78.6 \%)$ & 0.65 \\
Ki-67 index & $9(17.3 \%)$ & $6(21.4 \%)$ & \\
$\quad$ positive rate \% & $17.9 \pm 1.5$ & $22.8 \pm 2.0$ & 0.052 \\
mean \pm SD & & & \\
\end{tabular}

DCIS = ductal carcinoma in situ; DCIS-Mi = ductal carcinoma in situ with microinvasion; SD = standard deviation. 

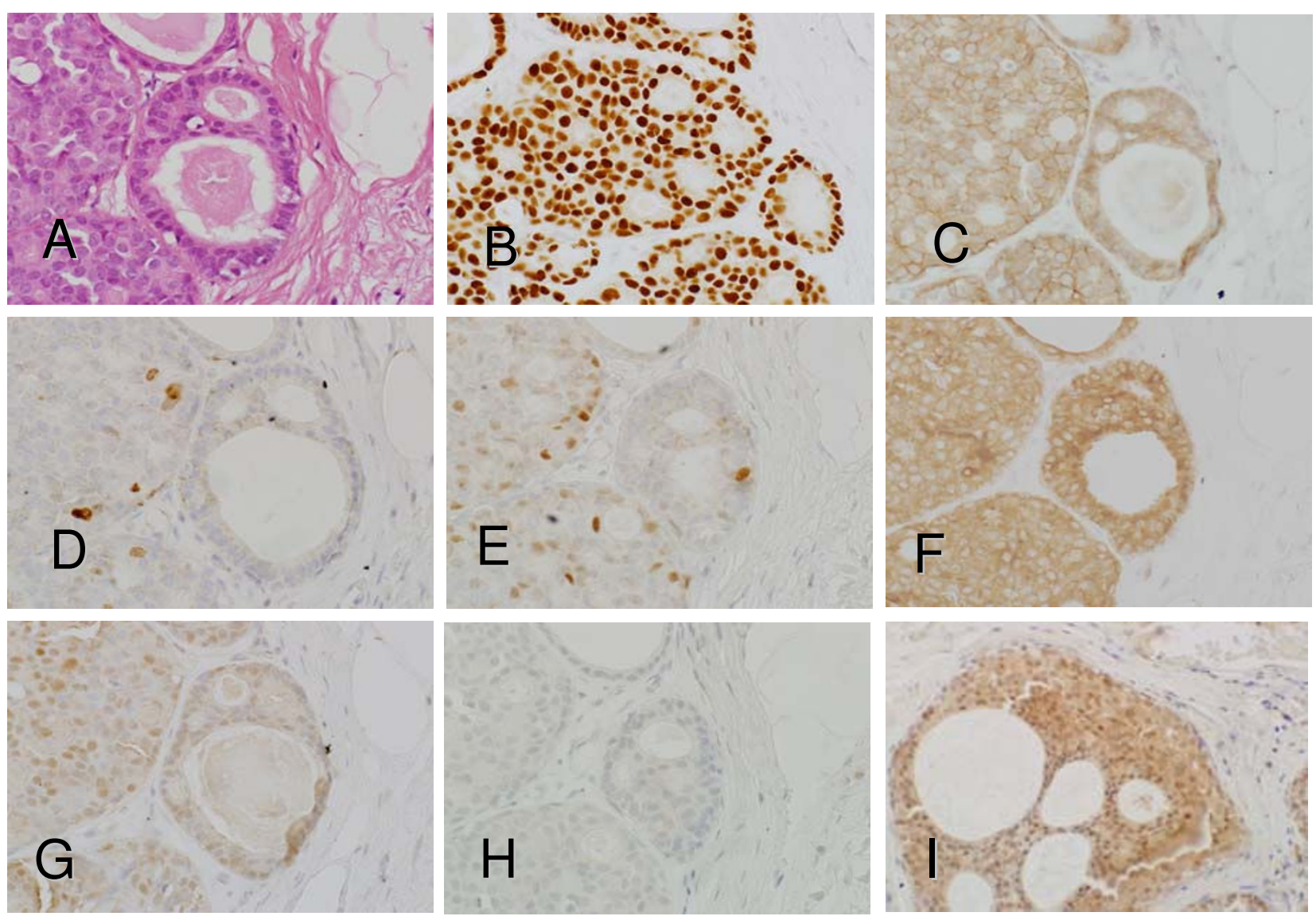

Figure I

Representative microscopic views of immunohistochemical detection. Intraductal component found in patients with DCIS, using A. hematoxylin-eosin (HE) staining, the frames show cells stained for B. estrogen receptor (ER), C. HER2, D. Ki67, E. P2I, F. BCL-2, G. BAX, and H. Survivin I, respectively. I. Survivin 2 shows moderately positive Survivin staining detected in another patient with DCIS. (original magnification $\times 200$ )

than in DCIS $(0.17 \pm 0.04 \%)(P=0.082)$. The expression of Bax, a promoting factor of apoptosis, was significantly higher in DCIS-Mi $(96.4 \%)$ than in DCIS $(71.2 \%)(P=$ $0.0028)$. The expression of survivin, an inhibiting factor of apoptosis, was also significantly higher in DCIS-Mi $(85.7 \%)$ than in DCIS $(55.8 \%)(P=0.0048)$, while the expression of another apoptosis inhibitor (Bcl-2) tended to be found more frequently in DCIS-Mi $(78.6 \%)$ than in DCIS (58.8\%), although this did not reach statistical significance $(P=0.071)$. There was no difference in the expression levels of p53, p21, cyclin D1, and Rb between DCIS and DCIS-Mi (Table 4). Because no cases were detected showing nuclear staining of survivin, in this study cases were regarded positive only when cytoplasmic staining was detectable. Based on this limitation the survivin expression showed a positive correlation with Bax expression $(P=0.038)$ and cases positive for survivin tended to show a higher apoptotic index $(P=0.077)$ (Table 5).

\section{Univariate and multivariate analyses for factors affecting invasion}

Univariate analysis for factors affecting invasion beyond the mammary ducts identified the presence of necrosis, positive Bax expression, and positive survivin expression to be significant factors and revealed apoptotic index, positive Bcl-2 expression, and Ki- 67 positivity to have a weak correlation with invasion. Multivariate analysis revealed that the presence of necrosis $(P=0.017$, odds ratio 5.19, 95\% Confidence Interval; CI 1.47-22.7), and positive survivin expression $(P=0.044$, odds ratio $3.9895 \%$ CI 1.11 17.2) were independent factors associated with invasion (Table 6). 
Table 4: Apoptosis-related factors in DCIS and DCIS-Mi

\begin{tabular}{|c|c|c|c|}
\hline & DCIS & DCIS-Mi & $P$-value \\
\hline Apoptotic Index (N/I000) & $1.7 \pm 0.4$ & $2.9 \pm 0.6$ & 0.082 \\
\hline \multicolumn{4}{|l|}{$\mathrm{Bcl}-2$} \\
\hline negative & $2 \mathrm{I}(4 \mathrm{I} .2 \%)$ & $6(21.4 \%)$ & 0.071 \\
\hline Positive & $30(58.8 \%)$ & $22(78.6 \%)$ & \\
\hline \multicolumn{4}{|l|}{ Bax } \\
\hline negative & I 5 (28.8\%) & I (3.6\%) & 0.0028 \\
\hline Positive & 37 (7I.2\%) & 27 (96.4\%) & \\
\hline \multicolumn{4}{|l|}{ Survivin } \\
\hline negative & $23(44.2 \%)$ & $4(14.3 \%)$ & 0.0048 \\
\hline positive & $29(55.8 \%)$ & $24(85.7 \%)$ & \\
\hline \multicolumn{4}{|l|}{$p 53$} \\
\hline positive & 39 (76.5\%) & $23(82.1 \%)$ & 0.55 \\
\hline Negative & $12(23.5 \%)$ & 5 (I7.9\%) & \\
\hline \multicolumn{4}{|l|}{$\mathrm{p} 21$} \\
\hline positive & $36(69.2 \%)$ & $15(53.6 \%)$ & 0.17 \\
\hline negative & $16(30.8 \%)$ & $13(46.4 \%)$ & \\
\hline \multicolumn{4}{|l|}{ cyclinDI } \\
\hline positive & $36(70.6 \%)$ & $18(64.3 \%)$ & 0.57 \\
\hline Negative & 15 (29.4\%) & $10(35.7 \%)$ & \\
\hline \multicolumn{4}{|l|}{$\mathrm{Rb}$} \\
\hline positive & $35(68.6 \%)$ & $23(82.1 \%)$ & 0.18 \\
\hline negative & $16(31.4 \%)$ & 5 (17.9\%) & \\
\hline
\end{tabular}

DCIS = ductal carcinoma in situ; DCIS-Mi = ductal carcinoma in situ with microinvasion.

\section{Discussion}

The investigation of the biological factors of DCIS-Mi may yield some explanations to the progression from DCIS to IDC. In this study, we examined the intraductal components of both DCIS and DCIS-Mi for expression of these factors, but not the invasive components. The reasons for this were: the purpose of this study was to determine the difference between the intraductal components of DCIS and DCIS-Mi; it was difficult to evaluate invasive foci because of their small size; in some cases, invasive foci were undetectable on slides for immunohistochemical staining; in histological diagnosis, it was important to evaluate the most predominant area of each section. Results from the present analysis showed that the frequency of necrosis was significantly higher in DCIS-Mi compared with DCIS.

The important result obtained from our analysis of apoptosis-related factors was that the positive rate of survivin

Table 5: Relationship among apoptosis-related factors

\begin{tabular}{llll}
\hline & Apoptosis index & Survivin & Bax \\
\hline $\mathrm{Bcl}-2$ & 0.11 & 0.65 & 0.042 \\
Bax & 0.018 & 0.038 & - \\
Survivin & 0.077 & - & - \\
\hline
\end{tabular}

expression was significantly higher in DCIS-Mi than in DCIS $(P=0.0048)$. The survivin gene, shown to be expressed in proliferating cells such as fetal and various cancer cells, is known to be a member of the IAP family which promotes cell proliferation and inhibits apoptosis. In particular, because survivin is expressed specifically in cancer cells and proliferating cells, this gene is likely to be involved in cell proliferation and/or differentiation $[29,30]$.

Previous reports have shown that, in invasive ductal carcinoma of the breast, survivin expression is significantly higher in the invasive foci than in the intraductal components and that high nuclear expression of survivin in the invasive foci is associated with a higher risk of recurrence and mortality $[19,30]$. However, there have also been reports that showed no correlation between survivin expression and prognosis in patients with breast cancer $[27,31]$, suggesting that its prognostic value is controversial. With the antibody used in this present study, survivin-specific staining in the nucleus was barely detectable, and therefore we relied upon cytoplasmic staining for the evaluation of survivin expression. Reasons for the lack of nuclear expression in this study remain unclear and must be sought in further study on survivin splice variants.

There have been many studies reporting that $\mathrm{Bcl}-2$, an apoptosis inhibitor, shows a positive correlation with hormone receptors in breast cancer tissues and is a favorable prognostic factor [26]. In addition, it has been reported that the expression of an apoptosis promoter Bax is associated with the degree of local recurrence in DCIS [32]. Furthermore, the relation between Bcl-2 and Bax is under debate with some reports showing a direct correlation between them and others showing no such correlation [33].

In our present results, the Bax expression was significantly higher $(P=0.0028)$ and the $\mathrm{Bcl}-2$ expression tended to be slightly higher $(P=0.071)$ in DCIS-Mi compared with DCIS. These results show a positive correlation between Bax and Bcl-2 and their increased expression with the progression from DCIS to DCIS-Mi. Thus, this may suggest that the specific interaction between Bax and $\mathrm{Bcl}-2$ is involved in apoptosis during this progression.

In our present study, we also found a tendency for higher apoptotic and Ki-67 indices in DCIS-Mi relative to DCIS. It is well known that these indices are higher in invasive ductal carcinoma of the breast than in fibroadenoma, a benign breast tumor. In DCIS, it has been shown that proliferation and apoptosis markers are higher in poorly-differentiated tumors than in well-differentiated tumors, which has led some investigators to believe that the differ- 
Table 6: Univariate and multivariate analyses according to microinvasion

\begin{tabular}{|c|c|c|c|c|c|c|}
\hline & \multicolumn{3}{|c|}{ Univariate analysis } & \multicolumn{3}{|c|}{ Multivariate analysis } \\
\hline & Odds ratio & $95 \% \mathrm{Cl}$ & $P$-value & Odds ratio & $95 \% \mathrm{Cl}$ & $P$-value \\
\hline Necrosis (present vs. absent) & 5.56 & $|.84-20.9|$ & 0.0017 & 5.19 & $1.45-22.7$ & 0.017 \\
\hline Apoptotic index $(\geqq 1000$ of positive cells vs. $<1 / 1000)$ & 0.40 & $0.14-1.04$ & 0.061 & 0.82 & $0.24-2.75$ & 0.74 \\
\hline $\mathrm{Ki}-67$ index $(\geqq 20 \%$ of positive cells vs. $<20 \%)$ & 0.44 & $0.15-1.18$ & 0.10 & 0.89 & $0.24-3.24$ & 0.86 \\
\hline Bcl-2 (positive vs. negative) & 2.57 & $0.93-7.95$ & 0.071 & 3.49 & $1.04-13.3$ & 0.051 \\
\hline Bax (positive vs. negative) & 10.92 & $2.02-203.9$ & 0.0028 & 5.21 & $0.70-111.1$ & 0.16 \\
\hline Survivin (positive vs. negative) & 4.76 & $1.57-17.9$ & 0.0048 & 3.98 & $1.11-17.2$ & 0.044 \\
\hline
\end{tabular}

$\mathrm{Cl}$, confidence interval

ence between DCIS and invasive carcinoma is a relative decrease in apoptosis [26]. Taken together, it has been suggested that both cell proliferation and apoptosis are enhanced in DCIS-Mi as compared to DCIS.

Furthermore, multivariate analysis for apoptosis-related factors affecting invasion, identified the presence of necrosis $(P=0.017)$ and high survivin expression $(P=0.044)$ as statistically significant factors. We also demonstrated that the frequency of apoptosis $(P=0.077)$ and nuclear grade $(P=0.081)$ tended to be higher in cases with positive immunolabeling for survivin, suggesting that survivin could be a marker reflecting the biological characteristics of DCIS and DCIS-Mi. In addition, there was a positive correlation between the expression of the anti-apoptotic factor survivin and that of an apoptosis promoter $\operatorname{Bax}(P=$ 0.038 ). These findings suggest that a balance is maintained in DCIS-Mi between survivin and Bax.

These results revealed that, compared to DCIS, DCIS-Mi is histologically associated with necrotic focus more commonly, and with a significantly higher expression of apoptosis-related factors, including survivin and Bax. In other words, DCIS-Mi is characterized by a slightly elevated cell proliferation ability and a tendency for enhanced apoptosis, which could increase cell death and subsequently promote the formation of necrotic foci [34]. In clinical settings, survivin may prove to be a useful marker to indicate a difference in biological features between DCIS and DCIS-Mi, and it could become one of the parameters used to determine whether adjuvant systemic therapy or surviving-inhibiting therapy should be given to patients with DCIS.

\section{Conclusion}

Compared with DCIS, DCIS-Mi is characterized by a slightly elevated cell proliferation capacity and enhanced apoptosis within the intraductal lesion, which are thought to promote the formation of cell necrotic foci. Furthermore, survivin is one of the markers indicating the difference in biological features between DCIS and DCIS-Mi, and further investigation of this marker is required to determine if this difference in expression could serve as an indicator for identifying which patients would benefit from adjuvant systemic therapy.

\section{Competing interests}

The authors declare that they have no competing interests.

\section{Authors' contributions}

$\mathrm{HI}$ conceived the design and drafted the manuscript. YO, $\mathrm{YY}, \mathrm{ZZ}$ performed the immunohistochemistry and the statistical analysis. TT, MI, HY collected the patients' data. YH and KI participated in the histological study design. HI supported the study financially. All authors read and approved the final manuscript.

\section{Acknowledgements}

The authors wish to thank Mrs. Mariko Nishio and Miss. Yu Ohgaki for their excellent technical support.

\section{Grant support:}

Ministry of Health, Labour and Welfare of Japan grant-in-aid for scientific research $60001604-01$. The costs of publication of this article were defrayed in part by the payment of page charges. This article must therefore be hereby marked advertisement in accordance with 18 U.S.C. Section 1734 solely to indicate this fact.

\section{References}

I. Page DL, Dupont WD, Rogers LW, Landenberger M: Intraductal carcinoma of the breast: follow-up after biopsy only. Cancer 1982, 49(4):75I-758.

2. Tsikitis VL, Chung MA: Biology of ductal carcinoma in situ classification based on biologic potential. Am J Clin Oncol 2006, 29(3):305-310.

3. Page DL, Dupont WD, Rogers LW, Jensen RA, Schuyler PA: Continued local recurrence of carcinoma 15-25 years after a diagnosis of low grade ductal carcinoma in situ of the breast treated only by biopsy. Cancer 1995, 76(7): I 197-1200.

4. Tang P, Hajdu SI, Lyman GH: Ductal carcinoma in situ: a review of recent advances. Curr Opin Obstet Gynecol 2007, I 9(1):63-67.

5. Greene FL, Page DL, Fleming ID, Haga T: Staging Manual. 6th edition. Philadelphia: Lippincott-Raven; 2002.

6. Silver SA, Tavassoli FA: Mammary ductal carcinoma in situ with microinvasion. Cancer 1998, 82 (1 2):2382-2390.

7. Adamovich TL, Simmons RM: Ductal carcinoma in situ with microinvasion. Am / Surg 2003, I86(2): II2-II6.

8. Cavaliere A, Scheibel M, Bellezza G, Colella R, Vitali R, Gori S, Aristei $C$, Rulli $A$, Sidoni $A$ : Ductal carcinoma in situ with microinvasion: clinicopathologic study and biopathologic profile. Pathol Res Pract 2006, 202(3): $131-135$. 
9. Bijker N, Peterse JL, Duchateau L, Robanus-Maandag EC, Bosch CA, Duval C, Pilotti S, Vijver MJ van de: Histological type and marker expression of the primary tumour compared with its local recurrence after breast-conserving therapy for ductal carcinoma in situ. Br J Cancer 200I, 84(4):539-544.

10. Kerlikowske K, Molinaro A, Cha I, Ljung BM, Ernster VL, Stewart K, Chew K, Moore DH 2nd, Waldman F: Characteristics associated with recurrence among women with ductal carcinoma in situ treated by lumpectomy. I Natl Cancer Inst 2003, 95(22): I692-1702.

II. Provenzano E, Hopper JL, Giles GG, Marr G, Venter DJ, Armes JE: Histological markers that predict clinical recurrence in ductal carcinoma in situ of the breast: an Australian populationbased study. Pathology 2004, 36(3):221-229.

12. Barnes DM, Bartkova J, Camplejohn RS, Gullick WJ, Smith PJ, Millis RR: Overexpression of the c-erbB-2 oncoprotein: why does this occur more frequently in ductal carcinoma in situ than in invasive mammary carcinoma and is this of prognostic significance? Eur J Cancer 1992, 28:2-3.

13. Bobrow LG, Happerfield LC, Gregory WM, Springall RD, Millis RR: The classification of ductal carcinoma in situ and its association with biological markers. Semin Diagn Pathol 1994 I I(3): | 99-207.

14. Leal CB, Schmitt FC, Bento MJ, Maia NC, Lopes CS: Ductal carcinoma in situ of the breast. Histologic categorization and its relationship to ploidy and immunohistochemical expression of hormone receptors, p53, and c-erbB-2 protein. Cancer I995, 75(8):2123-2131.

15. Iwase H, Ando $Y$, Ichihara S, Toyoshima S, Nakamura T, Karamatsu S, Ito $\mathrm{Y}$, Yamashita H, Toyama T, Omoto $\mathrm{Y}$, et al:: Immunohistochemical analysis on biological markers in ductal carcinoma in situ of the breast. Breast Cancer 200I, 8(2):98-104.

16. Roka S, Rudas M, Taucher S, Dubsky P, Bachleitner-Hofmann T, Kandioler $D$, Gnant $M$, Jakesz R: High nuclear grade and negative estrogen receptor are significant risk factors for recurrence in DCIS. Eur J Surg Oncol 2004, 30(3):243-247.

17. Zhao YG, Xiao AZ, Park HI, Newcomer RG, Yan M, Man TG, Heffelfinger SC, Sang QY: Endometase/Matrilysin-2 in human breast ductal carcinoma in situ and its inhibition by tissue inhibitors of metalloproteinases-2 and -4: A putative role in the initiation of breast cancer invasion. Cancer Research 2004, 64(2):590-598.

18. Tamm I, Wang Y, Sausville E, Scudiero DA, Vigna N, Oltersdorf T, Reed JC: IAP-family protein survivin inhibits caspase activity and apoptosis induced by Fas (CD95), Bax, caspases, and anticancer drugs. Cancer Res 1998, 58(23):5315-5320.

19. Kennedy SM, O'Driscoll L, Purcell R, Fitz-Simons N, McDermott EW, Hill AD, O'Higgins NJ, Parkinson M, Linehan R, Clynes M: Prognostic importance of survivin in breast cancer. Br J Cancer 2003, 88(7): $1077-1083$.

20. Kayaselcuk F, Nursal TZ, Polat A, Noyan T, Yildirim S, Tarim A, Seydioglu G: Expression of survivin, bcl-2, P53 and bax in breast carcinoma and ductal intraepithelial neoplasia (DIN Ia). J Exp Clin Cancer Res 2004, 23(I): I05-II 2.

21. Barnes N, Haywood P, Flint P, Knox WF, Bundred NJ: Survivin expression in in situ and invasive breast cancer relates to COX-2 expression and DCIS recurrence. Br J Cancer 2006, 94(2):253-258.

22. Silverstein MJ, Poller DN, Waisman JR, Colburn WJ, Barth A, Gierson ED, Lewinsky B, Gamagami P, Slamon DJ: Prognostic classification of breast ductal carcinoma-in-situ. Lancet 1995, 345: I I 54- I I 57.

23. Monteagudo C, Merino MJ, San-Juan J, Liotta LA, Stetler-Stevenson WG: Immunohistochemical distribution of type IV collagenase in normal, benign, and malignant breast tissue. $\mathrm{Am} J$ Pathol 1990, I 36(3):585-592.

24. Al-Joudi F, Iskandar Z, Hasnan J, Rusli J, Kamal Y, Imran A, Ahmed M, Zakaria J: Expression of survivin and its clinicopathological correlations in invasive ductal carcinoma of the breast. Singapore Med J 2007, 48(7):607-6I4.

25. Yamamoto Y, Ibusuki M, Okumura Y, Kawasoe T, Kai K, lyama K, Iwase $\mathrm{H}$ : Hypoxia-inducible factor I alpha is closely linked to an aggressive phenotype in breast cancer. Breast Cancer Res Treat 2008, I I0(3):465-75

26. Kobayashi $S$, Iwase $H$, Ito $Y$, Yamashita $H$, Iwata $H$, Yamashita T, Ito K, Toyama T, Nakamura T, Masaoka A: Clinical significance of bcl-
2 gene expression in human breast cancer tissues. Breast Cancer Res Treat 1997, 42(2): |73-181.

27. Tanaka K, Iwamoto S, Gon G, Nohara T, Iwamoto M, Tanigawa N: Expression of survivin and its relationship to loss of apoptosis in breast carcinomas. Clin Cancer Res 2000, 6(1): I 27-I34.

28. Iwase H, Omoto $Y$, Iwata H, Hara $Y$, Ando $Y$, Kobayashi S: Genetic and epigenetic alterations of the estrogen receptor gene and hormone independence in human breast cancer. Oncology 1998, 55(Suppl I): I I-16.

29. Yamashita S, Masuda Y, Kurizaki T, Haga Y, Murayama T, Ikei S, Kamei $M$, Takeno S, Kawahara K: Survivin expression predicts early recurrence in early-stage breast cancer. Anticancer Res 2007, 27(4C):2803-2808

30. Hinnis AR, Luckett JC, Walker RA: Survivin is an independent predictor of short-term survival in poor prognostic breast cancer patients. Br J Cancer 2007, 96(4):639-645.

31. Chu JS, Shew JY, Huang CS: Immunohistochemical analysis of survivin expression in primary breast cancers. J Formos Med Assoc 2004, I03( I 2):925-931.

32. Rehman S, Crow J, Revell PA: Bax protein expression in DCIS of the breast in relation to invasive ductal carcinoma and other molecular markers. Pathol Oncol Res 2000, 6(4):256-263.

33. Kapucuoglu N, Losi L, Eusebi V: Immunohistochemical localization of $\mathrm{Bcl}-2$ and Bax proteins in in situ and invasive duct breast carcinomas. Virchows Arch 1997, 430(I): I7-22.

34. Mommers EC, van Diest PJ, Leonhart AM, Meijer CJ, Baak JP: Balance of cell proliferation and apoptosis in breast carcinogenesis. Breast Cancer Res Treat 1999, 58(2): 163-169.

\section{Pre-publication history}

The pre-publication history for this paper can be accessed here:

http://www.biomedcentral.com/1471-2407/8/287/pre pub
Publish with Bio Med Central and every scientist can read your work free of charge

"BioMed Central will be the most significant development for disseminating the results of biomedical research in our lifetime. "

Sir Paul Nurse, Cancer Research UK

Your research papers will be:

- available free of charge to the entire biomedical community

- peer reviewed and published immediately upon acceptance

- cited in PubMed and archived on PubMed Central

- yours - you keep the copyright 